\title{
Lógicas diferentes de instituições de ensino superior num mesmo sistema: os perfis das instituições de ensino politécnico em Portugal
}

\author{
Cláudia Urbano
}

\section{RESUMO}

O panorama de formação superior em Portugal mudou de forma significativa nas últimas quatro décadas, sobretudo com o crescimento do ensino politécnico. Alvo de frequentes modificações, o ensino superior tem estado na última década perante uma "nova era politécnica", com lógicas de ação das instituições de ensino politécnico que paralelamente à vertente de ensino se projetam em três novos campos de ação: formação pós-graduada, investigação e internacionalização. Com o objetivo de refletir sobre as suas lógicas de ação e os sentidos de missão, lançando também questões sobre o momento atual, são apresentados neste artigo os resultados de uma investigação junto das instituições de ensino politécnico em Portugal.

Palavras chave: ensino superior, ensino politécnico, perfis, Portugal. 


\section{Lógicas diferentes de instituciones de enseñanza superior en un mismo sistema: los perfiles de} las instituciones de enseñanza politécnica en Portugal

\section{RESUMEN}

El panorama de formación superior en Portugal cambió significativamente en las últimas cuatro décadas, sobre todo con el crecimiento de la enseñanza politécnica. Objeto de frecuentes modificaciones, la enseñanza superior ha estado en la última década frente una "nueva era politécnica", con lógicas de acción de las instituciones de enseñanza politécnica que paralelamente a la vertiente de enseñanza se proyectan en tres nuevos campos de acción: formación posgraduada, pesquisa e internacionalización. Con el objetivo de reflexionar sobre sus lógicas de acción y los sentidos de misión, introduciendo también cuestiones sobre o momento actual, son presentados en este artículo los resultados de una investigación junto a las instituciones de enseñanza politécnica en Portugal.

Palabras clave: enseñanza superior, enseñanza politécnica, perfiles, Portugal.

\section{Different logics of higher education institutions in the same system: the profiles of polytechnical institutions in Portugal}

\section{ABSTRACT}

The panorama of higher education in Portugal has changed significantly over the last four decades, especially with the growth of polytechnical education. As a target of frequent changes, higher education has been in the last decade facing a "new polytechnical era", with the logic of action of the polytechnical education institutions that, in parallel to teaching, are projected in three new fields of action: postgraduate training, research and internationalization. In order to reflect on their logic of action and senses of mission and raising at the same time important questions about the current moment in the field of education, this article presents the results of a research about polytechnical institutions in Portugal.

Key words: higher education, polytechnic education, profiles, Portugal. 


\section{Introdução}

O panorama de formação superior em Portugal alterou-se de forma significativa nas últimas quatro décadas. Expandiu-se, diversificou-se, cresceu, heterogeneizou-se. O sistema de ensino superior tornou-se binário, inicialmente apenas universitário, e mais tarde, na década de 1970, criado e afirmado ensino politécnico. Ao longo do tempo, o politécnico ganhou espaço: aumentou em número de instituições, diversificou-se nas áreas de conhecimento oferecidas, alargou-se pelo território nacional, e hoje apresenta uma posição firme e sustentada no mercado de formação superior em Portugal. Em duas décadas, triplicou o número de lugares a concurso, reduzindo de forma substancial o hiato que o afastava do seu congénere universitário no quadro de oferta de vagas no início dos anos 1990. Como afirma Mourato (2014), a sua evolução pode ser genericamente retratada como uma história de sucesso, ainda que registe algumas situações de insucesso.

O perfil das instituições de ensino politécnico tem sido alterado, ajustado a novas diretrizes políticas e a novas realidades sociais. A ligação ao ensino secundário, com a formação pós-secundária através de cursos de especialização tecnológica, a inserção em redes nacionais e internacionais de ensino e de investigação, o incentivo à mobilidade docente e discente, o estabelecimento de protocolos de cooperação, o desenvolvimento de atividades científicas, entre outros, têm-se constituído como novos campos de ação por parte de instituições de ensino politécnico. Pela sua emergência mais recente no ensino superior, face à posição hegemónica do ensino universitário, e pela procura de definição de uma identidade própria dentro do ensino superior (Urbano, 2015), o ensino politécnico é, dos dois, o mais "camaleónico", com sistemáticas alterações na sua organização, composição e ação.

Com o objetivo de definir o perfil — ou os perfis - das instituições, foi realizada, através de uma metodologia quantitativa, uma pesquisa junto de instituições de ensino politécnico em Portugal em 2010, que tomamos como ponto de partida neste artigo. A partir dessa definição, e perante novos desafios, estamos em condições de refletir sobre o momento atual por que passa o ensino politécnico.

Assim, apresentamos um breve olhar sobre o ensino politécnico em Portugal, seguindo-se a metodologia utilizada na pesquisa, os resultados obtidos, os novos desafios e, por fim, as considerações finais acerca deste tema.

\section{O ensino politécnico em Portugal}

O ensino politécnico em Portugal surgiu no ensino superior como subsequente do ensino médio técnico, no seguimento de alterações estruturais ocorridas no sistema de ensino e na sociedade em geral. A interpretação das transformações no ensino médio não é alheia a uma leitura das alterações ocorridas no sistema político, na estrutura social, na economia e no mercado de trabalho. Os projetos políticos, os projetos das classes profissionais, os projetos das organizações e associações a elas relacionadas incidiriam sobre o desenho do ensino técnico e do ensino superior. A evolução do ensino técnico, em particular do ensino industrial, nos níveis médio e superior deveu-se muito à intervenção, sem par na história das instituições de ensino em Portugal, de grupos de engenheiros e engenheiros técnicos que se apresentavam, à data, com diferenciados "benefícios materiais e simbólicos ligados às posições sociais" (Grácio, 1998: 10). Para além dessa diferenciação, exteriorizavam-se lutas de interesses que existiam entre si, através de uma pressão específica sobre o ensino técnico. Sustentando essa diferença, criam-se legalmente as condições para que no ensino superior surja numa nova modalidade: o ensino superior curto. Com o intuito de dar resposta a uma cada vez maior frequência de ensino superior, o ensino superior curto surge como proposta nos finais da década de 1960, primeiro com Galvão Teles e depois com José Hermano Saraiva (Grácio, 1998), sendo concretizado e definido com a 
política educativa de Veiga Simão. As primeiras alterações no ensino médio técnico terão ocorrido anos antes, em finais de 1968, com José Hermano Saraiva como ministro da Educação, ainda que de forma não completa, ao não ser definido o nível de ensino a que corresponderia. O projeto político assente na expansão e diversificação do ensino, apresentado por Veiga Simão em 1971, no qual os institutos politécnicos integrariam o ensino superior juntamente com as universidades e outros estabelecimentos de ensino similar, constitui-se como um marco importante. Por razões de diversa ordem, nomeadamente políticas, esse projeto só viria a ser concretizado mais tarde. A Revolução de Abril daria ao país e à governação outras prioridades que não a da alteração da estrutura de ensino superior.

O ensino superior politécnico, sucedâneo do ensino superior de curta duração, foi apresentado de forma estruturada pela reforma Veiga Simão (com a Lei 5/73, de 25 de julho, e o Decreto-Lei 402/73, de 11 de agosto). A designação do "ensino superior de curta duração" para "ensino superior politécnico" foi consagrada em definitivo com a partir do Decreto-Lei 513-T/79, de 26 de dezembro, com "dignidade idêntica ao universitário" e com objetivos de formação superior específicos, de carácter e inserção regional, assegurando uma formação de duração mais reduzida, de índole prática e em articulação com as atividades produtivas. A rede de ensino superior politécnico fica constituída a partir da Lei 29/80, de 28 de julho, rede essa fortemente regionalizada, importante para o desenvolvimento local destas regiões, através da formação de técnicos com uma preparação prática, e em áreas científicas e económicas específicas de cada região (Urbano, 2015).

A Lei de Bases do Sistema Educativo (LBSE) de 1986 constitui-se como o marco legislativo da construção binária do ensino superior, onde ao ensino superior politécnico é atribuído o objetivo de proporcionar formação superior assente em conhecimentos científicos de índole teórica e prática e com aplicações com vista ao exercício de atividades profissionais. Um segundo marco importante foi a Lei 49/2005, como alteração à LBSE e à lei de financiamento das instituições de ensino superior, na sequência do processo de Bolonha de construção de um espaço europeu de formação superior. Diversos textos normativos (Lei 49/2005, de 30 de agosto; RJIES; Lei 62/2007; decreto-lei 205/2009), decorrentes de diferentes contextos sociais, políticos, económicos nacionais e internacionais, têm de certa forma alterado a organização, a definição e a missão (ou missões) do ensino superior em geral e do ensino politécnico em particular. No preâmbulo do decreto-lei 205/2009 há referência à contribuição das universidades para o desenvolvimento científico tendo a investigação científica como elemento central da carreira universitária, enquanto aos politécnicos cabe a função de atrair mais alunos, criar fileiras de ensino curto e promover uma inserção regional do ensino superior ou, como refere Galego, "centrar-se numa formação de natureza profissional ou de especialização em detrimento de uma formação de natureza exclusivamente científica" (Galego, 2016: 19).

A partir da sua organização em dois subsistemas, o sistema de ensino superior português é certamente um sistema heterogéneo. A nossa questão de partida era a de procurar saber se, perante as alterações das políticas públicas de ensino superior, estaríamos perante subsistemas homogéneos no seu interior. Para tal, optámos por centrar a nossa pesquisa naquele que era mais "jovem" e que mais desafios teria na busca de construção de uma identidade concreta (Urbano, 2015).

\section{Modelos teóricos de instituições de ensino superior}

Classificar instituições de ensino superior é uma estratégia eficiente para o controlo de características institucionais em investigação académica e para o desenvolvimento de políticas baseadas em diferentes 
tipos de instituições, em sistemas de governança centralizados (Shin, 2009). Assim, tanto investigadores como policy makers utilizaram diversos critérios, como a dimensão institucional, a localização (por exemplo, urbano, rural, etc.), o enfoque de missão (ensino, investigação, etc.), o foco da educação (por exemplo, educação religiosa, educação de minorias, etc.) para desenvolver tipologias de instituições de ensino superior.

$\mathrm{Na}$ análise que faz do novo Espaço Europeu de Ensino Superior (EEEE), Birnbaum (referido por Amaral et al., 2006: 20-21) constrói vários perfis de instituições entre as quais se encontram as colegiais, as burocráticas, as políticas e as anárquicas, terminando depois naquela que considera a ideal: a cibernética. Nesta linha de pensamento, são o tipo de controlo, a abertura ou fechamento do sistema, e o estabelecimento de parcerias fortes ou fracas que diferenciam as instituições e as enquadram nos diferentes perfis.

Bathmaker et al. (2007: 9) chegam igualmente a quatro modelos diferentes de instituições, na conjugação de quatro conceitos de limite distintos (o de competência, o de poder, o de identidade e o de eficiência). Resumidamente, eles são: um modelo A, uma instituição de ensino superior como um grande provedor de ensino adicional e superior através de fusão; um modelo B, um college especializado transferindo-se do sector da educação adicional para $\mathrm{O}$ sector do ensino superior; um modelo $\mathrm{C}$, um college de educação adicional que suporta uma pequena quantidade de ensino superior e mantém um foco predominante na educação adicional, e um modelo $\mathrm{D}$, um estabelecimento de ensino adicional que oferece uma quantidade substancial de ensino superior e que separa a sua organização de educação adicional e superior.

Tanto a proposta de Birnbaum como a de Bathmaker et al. servem como referência. Contudo, a nossa opção é a de centrarmos a nossa pesquisa na leitura das lógicas de ação e representação e não na forma como as instituições de ensino se encontram organizadas e estruturadas. Para isso, construímos um modelo que sintetize os vários tipos de instituições de ensino superior, a partir das suas ações e representações, e acreditamos que a conclusão a que se chegará será coincidente e complementar à de Birnbaum: ambas apontam no sentido da diversidade.

Outras classificações existem: a classificação Carnegie, nos EUA, da qual resultam vinte perfis baseados no número de programas e de graduados de cada nível; no Japão, com base na dimensão de cada nível de programa, as instituições de ensino superior são classificadas em um de cinco perfis possíveis; na China, a partir do volume de fundos de investigação governamental e de publicação de artigos em revistas internacionais, as instituições podem tomar um de nove perfis. Curiosamente, o estudo de Shin (2009) aponta para um resultado semelhante ao nosso, como veremos mais adiante, tendo sido considerada a performance de investigação, a quantidade de títulos de doutoramento e mais de 100 artigos em revistas internacionais por ano. A partir de uma estratégia de classificação às disciplinas/áreas, resultam 3 perfis de instituições de ensino superior universidade de investigação, universidade ativa de investigação, e universidade doutoral.

Esta diversidade, ou diversificação, assentará certamente numa premissa: a de que essas múltiplas vias poderão ser uma resposta organizacional natural aos desafios da educação de massas, ao aumento da concorrência a uma maior diferenciação institucional, a fim de adaptar mais as lógicas de ação das instituições e os seus programas às necessidades locais específicas e acomodar uma população crescente de estudantes com um background mais plural em termos educacionais, sociais e culturais (Rossi, 2010). Isto porque uma tendência para uma maior ou menor diversidade dos sistemas de ensino superior será resultado de conjuntos diferentes de relações que as instituições de ensino superior têm com o seu meio (Horta et al., 2008). 


\section{Metodologia}

Realizámos uma pesquisa de diagnóstico sobre as instituições de ensino superior politécnico em Portugal, a partir de um inquérito por questionário, com base em conceitos e indicadores adotados pelo Inquérito ao Potencial Científico e Tecnológico Nacional (IPCTN), por forma a haver uma base de referência e de comparação com resultados nacionais e internacionais.

O questionário contemplou os seguintes blocos temáticos: caracterização da unidade de ensino; recursos humanos em termos de quantidade de docentes a tempo integral e respetivos graus académicos; questões relacionadas com o ensino, designadamente proposta de novos cursos, descrição do Processo de Bolonha na unidade de ensino, existência de cursos pós-graduados; atividades de investigação y desenvolvimento (i\&d); atividades de divulgação junto da comunidade; pertença a redes/consórcios; e considerações gerais acerca do grau de concretização dos objetivos enunciados e definição de atividades recentes e futuras.

Todas as instituições de ensino politécnico, públicas ou privadas foram inquiridas por via eletrónica (com reforço telefónico de incentivo à participação), totalizando 168 unidades de análise à data de 2010: 15 institutos politécnicos públicos, 79 escolas superiores e institutos superiores públicos, 59 instituições privadas e 15 escolas politécnicas públicas inseridas em universidades. O preenchimento do questionário foi feito, na maioria dos casos, pelos diretores/presidentes das unidades orgânicas. A taxa de resposta foi de $27 \%$, estando dentro dos valores expectáveis para uma inquirição via postal e direcionada a dirigentes (Manfreda et al., 2008).

$\mathrm{Na}$ impossibilidade de recolher informação junto da totalidade das instituições, ou seja, na impossibilidade de um recenseamento por ausência de participação, consideramos as respostas obtidas como fazendo parte de uma amostra de conveniência, voluntária, cujos resultados não podem ser generalizados à população alvo. Contudo, considera-se ter conseguido obter um leque de instituições bastante diversificado, institucional e regionalmente falando, e que permite efetuar uma leitura pertinente sobre as instituições de ensino politécnico em Portugal. $\mathrm{O}$ conjunto de instituições que responderam ao questionário apresenta uma diversidade que será também ela caracterizadora do subsistema de ensino politécnico. Essa diversidade verifica-se, numa primeira abordagem em termos de caracterização, a várias dimensões: uma, temporal, pela sua maior ou menor antiguidade; outra, processual, pela existência ou não de alterações e de processos de fusão; outra, espacial, pelas suas localizações; outra, estatutária, pela autonomia ou dependência de outros organismos hierarquicamente superiores.

\section{Resultados}

As respostas obtidas provêm dos mais diversos pontos do país. Praticamente todos os distritos e regiões autónomas foram cobertos. Para além de uma diversidade regional, também é um facto que se dispõe de um quadro de participações bastante heterogéneo no que se refere à antiguidade das mesmas, com instituições mais antigas, das décadas de 1970 e 1980, outras do período de maior crescimento do ensino politécnico (década de 1990), e algumas mais recentes. Cerca de um terço das instituições orgânicas passou por um processo de fusão ou reintegração numa outra instituição, tendo esse processo coincidido com o processo de reestruturação do próprio ensino politécnico. Para além da acoplagem a uma unidade-mãe, seja ela universitária ou politécnica, aproximadamente metade das instituições passou por um processo de redesignação identitária.

Existe uma grande diversidade de instituições orgânicas em matéria de recursos humanos em termos de número de docentes e níveis de qualificação dos mesmos. Há também uma diferença substancial de oferta formativa entre as instituições de ensino participantes, desde aquelas que apresentam um leque variado de cursos às que se especializam em apenas 
um ou dois cursos superiores. A diferença de oferta estende-se pelo número de vagas e, consequentemente, número de alunos inscritos nas instituições.

A formação de $2^{\circ}$ ciclo passou, nos últimos anos, a ser uma nova aposta no e do ensino politécnico. Dos cursos de especialização e das pós-graduações aos mestrados integrados e, em condições muito específicas, aos doutoramentos em parceria com universidades, o leque de oferta formativa pós-graduada aumentou e diversificou-se, e constitui-se como uma das atuais missões das instituições de ensino politécnico. É inegável a importância que o desenho do novo paradigma de ensino superior, com o processo de Bolonha, veio ter nesta nova porta de formação superior em instituições politécnicas. Algumas instituições participam na oferta de formação pós-secundária, tendo alargado em 2009/2010 a formação direcionando-a a titulares de um curso secundário, com o ensino secundário incompleto ou de idade superior a 23 anos com experiência profissional relevante para o curso em questão, ou seja, como alternativa ou como "quase antecipação" ao ingresso no ensino superior.

Cerca de três quartos das instituições desenvolveu atividade de investigação e desenvolvimento no decorrer do ano letivo de 2009/2010. De entre as atividades de investigação, definido pelo Ministério da Ciência, Tecnologia e Ensino Superior, pela Fundação para a Ciência e a Tecnologia (FCT) e no IPCTN, consideram-se investigação fundamental os trabalhos, experimentais ou teóricos, empreendidos com a finalidade de obtenção de novos conhecimentos científicos sobre os fundamentos de fenómenos e factos observáveis, sem o objetivo específico de aplicação prática; por investigação aplicada entendem-se "trabalhos originais, também efetuados com vista à aquisição de novos conhecimentos, mas com uma finalidade ou um objetivo pré-determinados; e desenvolvimento experimental quando consiste na "utilização sistemática de conhecimentos existentes, obtidos por investigação e/ou experiência prática, com vista à instalação de novos materiais, produtos ou dispositivos, à instalação de novos processos, sistemas ou serviços, ou à melhoria significativa dos já existentes (OCDE, 1993). Quase metade das instituições afirma estar envolvida em projetos de investigação aplicada, um terço em projetos de desenvolvimento experimental e uma em cada cinco em investigação fundamental. Assim, seguindo o que em textos normativos estava definido como sendo do âmbito das instituições de ensino politécnico e do âmbito de instituições de ensino universitário, os tipos de investigação mais desenvolvidos por instituições orgânicas de ensino politécnico comportam, em primeiro lugar, objetivos pré-determinados de acordo com o que se considera investigação aplicada, e, em segundo lugar, objetivos de instalação de novos meios ou processos fazendo recurso sistemático a conhecimentos existentes, sustentando assim o desenvolvimento experimental.

Para o conjunto de 13 tipos diferentes de parcerias (quatro ligadas ao Estado, cinco ao ensino superior, dois a instituições sem fins lucrativos/centros tecnológicos ou outras instituições de interface com as empresas e outros dois tipos de empresas, de acordo com a classificação do IPCTN), predominam as parcerias com instituições de ensino superior público universitário e politécnico e instituições de ensino superior estrangeiras. Destacam-se ainda organismos do Estado (institutos não ligados ao ensino superior, direções-gerais, entre tantos outros), instituições privadas sem fins lucrativos/centros tecnológicos/outras instituições de interface em Portugal, e empresas em Portugal.

Das instituições que desenvolveram atividades de investigação, dois terços identificam a integração em programas e/ou redes de investigação, sendo na sua maioria os programas comunitários, as redes de investigação nacionais e os programas de investigação promovidos pela administração central. Seguem-se, depois, outros programas de investigação internacionais, os promovidos pela administração local e as redes internacionais de investigação. Pode-se daí perceber um considerável grau de iniciativa e participação em atividades de i\&d tanto nacionais como 
além-fronteiras. Perante estes dados, é possível questionar o âmbito estritamente local e regional ao qual tantas vezes se associam as iniciativas do ensino politécnico.

Foi dedicado um derradeiro ponto do questionário para levar as instituições de ensino politécnico a tecerem considerações gerais sobre os seus objetivos e atividades desenvolvidas, passados, atuais e futuros, procurando-se aferir o "sentido de missão" das instituições. O objetivo com melhor índice de concretização é o que se refere à oferta de formação graduada ao nível do $1^{\circ}$ ciclo de estudos superiores. Seguem-se, com um grau de concretização aceitável, a promoção de encontros científicos, o intercâmbio dentro da comunidade e o aprofundar de conhecimentos nas áreas de atuação. Ainda com uma maioria de opiniões encontram-se a oferta de formação pós-graduada, o apoio à docência e à investigação académica dos docentes. Na opinião dos respondentes, requerem alguma atenção em termos de concretização objetivos como a edição/divulgação, a prestação de serviços à comunidade, a promoção de interdisciplinaridade e a ligação com o ensino secundário. Os objetivos que carecem de maior concretização são o desenvolvimento experimental e o apoio à investigação científica.

Todas as atividades sofreram, para a maioria das instituições, um aumento global em quantidade e em intensidade de 2000-2005 para 2010. As atividades mais desenvolvidas - ações de formação, congressos/conferências/colóquios, cursos livres/seminários e prestação de serviços à comunidade - são as que mais cresceram em termos de quantidade. Reforçando o vínculo que as ligam à(s) comunidade(s) em que se inserem e que as envolvem, o objetivo de prestação de serviços é, de todos, o único que não apresenta nenhuma indicação de redução.

Os objetivos com maior importância no futuro são, no entender das instituições, o apoio à docência e à investigação académica dos docentes, seguindo-se o novo campo de atuação das instituições de ensino politécnico: a participação em redes nacionais e internacionais de investigação científica. Em sequência de prioridades surgem o aprofundamento de conhecimentos e a prestação de serviços, seguindo-se a promoção de intercâmbio científico e de interdisciplinaridade, e o estabelecimento de protocolos com outras instituições de ensino politécnico e universitário, a fim de concretizar esse intercâmbio.

Segundo as instituições, o Processo de Bolonha trouxe um aumento da oferta de cursos pós-graduados, o estabelecimento de parcerias além-fronteiras, a investigação e a procura de ensino por parte do público.

Um dos aspetos que mais se destaca prende-se com a diversidade que foi sendo encontrada nos vários indicadores em análise. Essas diferenças, que são bastante fortes em muitos casos, contrariam uma certa tendência para ver o ensino politécnico de forma homogénea, sem considerar a diversidade institucional, estrutural, programática, histórica existente. A partir da perceção dessa diversidade, foi selecionado um conjunto alargado de indicadores que se considerassem como representativos das diferentes dimensões envolvidas (recursos, ensino, investigação, ligação à comunidade, entre outras). Feita essa seleção, recorreu-se a uma análise multivariada dos dados (com recurso à Análise de Correspondências Múltiplas (ACM) no software para análise de dados SPAD-N, Système Portable pour l'Analyse des Donnés) a partir de informação de caracterização e das ações desenvolvidas. Foi possível, com os resultados obtidos e que são representativos das instituições participantes no estudo, construir uma proposta de tipologia de instituições de ensino politécnico, baseada em três perfis-tipo resultantes de classificação automática: um perfil (30\%) de unidade de ensino educativa, um perfil $(56 \%)$ de unidade de ensino científica e um perfil (14\%) de unidade de ensino empreendedora. O primeiro perfil caracteriza-se de forma mais imediata pela inexistência de atividades de investigação e de redes, e por se centrar na constituição de 
parcerias com o objetivo de concretizar a formação pós-graduação; este perfil que decorre da ACM, no cruzamento com informação sobre as atividades desenvolvidas, apresenta forte presença de instituições que tinham cursos de mestrado a decorrer. O perfil de unidade de ensino científica surge com uma forte presença de instituições que desenvolvem projetos de investigação aplicada e/ou de desenvolvimento experimental, e com alguns objetivos moderadamente concretizados, nomeadamente a edição/divulgação, a oferta de cursos de formação não graduada, o apoio à docência e à investigação académica dos docentes, a promoção de ligação ao ensino secundário e a prestação de serviços à comunidade, transparecendo a ideia de que são objetivos que interessam, mas não os que concentram as energias destas instituições. O perfil da unidade de ensino empreendedora, ainda que correspondendo a uma minoria mas forte em consistência interna, diferencia-se dos restantes pela fortíssima ligação ao meio envolvente, sendo instituições cujo grau de concretização de objetivos como a prestação de serviços à comunidade, o intercâmbio dentro da comunidade, o apoio à docência e à investigação académica dos docentes e a edição e divulgação são referidos como muito concretizados, consolidando alguns dos objetivos a partir de parcerias municipais e com empresas.

Chamamos a atenção para o facto de, apesar de a tipologia ser baseada em dados empíricos e métodos estatísticos, poder haver uma diferenciação na aplicação da tipologia em função da área científica e ela poder ajustar-se mais a umas áreas que a outras, fator que aqui não controlámos devido à pluralidade de áreas científicas que algumas instituições de ensino politécnico apresentavam.

\section{Os novos desafios das instituições de ensino politécnico}

A questão da diversidade de funções, missões e perfis pode ser ainda mais complexa no momento atual, quando comparada com a que se colocava ao ensino superior em geral e ao politécnico em particular no início da década e uma vez consolidada a adaptação às diretrizes de Bolonha: há instituições de ensino com dimensões e modelos de organização muito diferentes; há instituições de ensino quase exclusivamente dedicadas à docência, e outras mais envolvidas na investigação científica; há instituições de ensino predominantemente académicas e outras predominantemente profissionalizantes. A educação superior é plural, porque plurais são os subsistemas de ensino e as suas instituições de ensino. As instituições diversificam-se em busca de novos caminhos, novos públicos, novos nichos de mercado (Teixeira et al., 2011), também um pouco como forma de melhor autossustentação, autonomia e, em alguns casos, sobrevivência.

Como refere Mora (2018), os sistemas de ensino superior têm a responsabilidade de ser responsáveis pela mudança na sociedade do conhecimento, sendo que essa responsabilidade pode manifestar-se de formas tão diversas como o empreendedorismo, a cooperação com o desenvolvimento regional, as relações universidade-empresa, a terceira missão das universidades, e que podem não ser exatamente coincidentes. Essa possível não coincidência, acrescentamos nós, pode ser mais um motor para a justificação da pluralidade de instituições possíveis de encontrar.

Como sugere o relatório da European University Association (EUA, 2013), a reestruturação do sistema de ensino superior e a racionalização da formação (i.e., do conjunto de cursos disponibilizados) são amplamente usadas como formas oportunas para resolver a prolongada perda de sentido e a crise que ameaça a própria existência de algumas instituições. Significa que o processo de desenvolvimento estratégico, com ações e metas assumidas dentro de uma unidade de ensino superior, vem reforçar a necessidade de cada instituição a pensar de forma colaborativa sobre o seu próprio futuro e as tendências que lhes são exteriores (Pires da Rosa et al., 2001), assim exista uma estratégia definida. Numerosos estudos 
no ensino superior têm argumentado que as instituições de ensino superior são pluralistas por defeito: a organização é construída em torno de campos com base em normas disciplinares específicas e valores, que muitas vezes são apenas vagamente conectados uns aos outros (Frølich et al., 2013).

A partir de alguns indicadores apontados em modelos propostos de avaliação de dimensões como a investigação (Patrício et al., 2018) e a internacionalização (Veiga, 2011), resumimos tendências que têm recentemente sido seguidas, regra geral, pelas instituições de ensino superior politécnico em Portugal.

Decorrente do processo de pós-modernidade (Santos, 1999) do ensino superior, a partir de novas orientações das políticas públicas nos últimos dez anos, foram adicionadas e reforçadas outras vertentes de desenvolvimento de atividades por parte das instituições de ensino politécnico. Houve um claro investimento e financiamento públicos na qualificação do corpo docente do ensino politécnico, com programas especiais de apoio à conclusão de doutoramentos, possibilitando paralelamente uma reestruturação da oferta formativa, da especialização e do desenvolvimento da investigação e divulgação científicas. Esse aumento do investimento na investigação é comprovado a partir dos números: para um total de 9M€ em 2000, em 13 anos o valor ultrapassa os 100M€, tendo sofrido entretanto uma retração para os 50M€ em 2016 e 37M€ em 2017 (dados da Fundação para a Ciência e a Tecnologia). Este último ano tem a particularidade de ser o primeiro em que há um quase equilíbrio na divisão do financiamento para concursos gerais e para concursos específicos.

Relativamente à formação pós-graduada, as estatísticas nacionais apontam para um aumento do número de inscritos em mestrado: entre 2010 e 2018, subiu de aproximadamente 45000 para 59 000. Sabendo que o peso dos inscritos no ensino politécnico ronda os 30\% do valor total de inscritos no ensino superior em Portugal e que a quantidade de alunos a frequentar formação graduada $\left(1^{\circ}\right.$ ciclo/licenciatura, como oferta dominante no ensino politécnico) diminuiu, estimamos que o aumento da população estudante em pós-graduação tenha tido repercussões diretas na oferta e frequência de mestrados de ensino politécnico, no sentido do seu aumento.

É evidente também uma abertura à aceitação de candidaturas de instituições de ensino politécnico a programas de financiamento científico e desenvolvimento tecnológico, tendo sido correspondida tanto em número crescente de candidaturas como em volume de financiamento recebido. Ainda que um claro pendor do financiamento do lado das universidades (cerca de 90\% do bolo das despesas é canalizado para atividades de i\&d em universidades, face aos $10 \%$, em média, destinadas a instituições de ensino politécnico), entre 2007 e 2016 (dados da Direção-Geral de Estatísticas de Educação e Ciência de Portugal) o volume de despesas em i\&d para o politécnico mais que duplicou em termos absolutos. De entre os três tipos de investigação, a investigação aplicada recebe, no caso do politécnico, cerca de dois terços de financiamento para este subsistema (na universidade, o financiamento da investigação fundamental e da aplicada é muito equilibrado, com cerca de 40\% para cada tipo de investigação).

Também nos últimos anos se regista um aumento crescente de ingressos e frequência de cursos de ensino politécnico por parte de alunos estrangeiros, com recrutamentos além-fronteiras, seja de estudantes originários de países da Comunidade dos Países de Língua Portuguesa (CPLP) ou de países não lusófonos, a partir de acordos bilaterais e multilaterais, de regimes especiais, de programas comunitários de mobilidade, de programas de intercâmbio, entre as mais diversas instituições (Alves, 2015). Em termos de frequência para formação completa, verifica-se uma subida na percentagem de alunos estrangeiros no ensino superior politécnico a partir de 2008/09 (Pedreira, 2014), sendo em 2012 de mais de 4\% no total de alunos inscritos neste subsistema (segundo 
os dados estatísticos da Direção-Geral de Estatísticas da Educação e Ciência (DGEEC) de Portugal). Em 2015, os institutos politécnicos de Bragança e do Porto destacavam-se entre as cinco instituições de ensino superior portuguesas que acolhem um maior número de estudantes inscritos ao abrigo do Estatuto do Estudante Internacional (fonte: DGEEC). Sobre as mobilidades outgoing de estudantes, no ano de 2012, dos mais de 10000 estudantes inscritos em programas de mobilidade internacional, cerca de $17 \%$ eram de instituições de ensino politécnico; em 2015, os estudantes em mobilidade são mais de 13 000, sendo que um em cada cinco é de uma instituição de ensino politécnica; em 2016, o crescimento é ainda mais notório, com mais de 22000 estudantes em mobilidade, dos quais $22 \%$ são do politécnico.

Ainda em associação com este último ponto, houve uma internacionalização da formação politécnica, com a oferta de cursos e/ou de instituições curriculares em língua estrangeira; além disso, essa internacionalização alastra-se à vertente da investigação científica, com a concretização de parcerias em programas internacionais de financiamento para investigação, na realização de semanas internacionais para pessoal docente e não docente, e em programas como o Tempus, Erasmus Mundus, entre outros. A internacionalização do pessoal docente e não docente das instituições de ensino politécnico e das suas atividades de investigação têm de facto vindo a ganhar importância (CHEPS, 2013) e o ensino politécnico português acompanha esta tendência (Mourato, 2014).

As notícias de cariz político no início do ano de 2018 dão conta que a oferta de formação superior de $3^{\circ}$ ciclo (doutoramentos) será em breve uma realidade no ensino politécnico, pelouro que era, e ainda é até à data, exclusivo das universidades. Essa possibilidade de oferta de doutoramentos estará dependente da avaliação da capacidade científica da unidade de ensino superior, e não do subsistema em que esta se integra, tendo para tal que demonstrar que produzem ciência na área em que pretendem a oferta dessa formação. Contudo, a inexistência de acesso ao emprego científico e a ausência de programas específicos para equipar laboratórios de i\&d limitam fortemente a excelência da investigação científica nas instituições de ensino politécnicos, o que poderá significar uma nova possibilidade mas com dificuldade de concretização. Essa dificuldade acresce quando falta definir melhor um modelo de avaliação de desempenho da investigação aplicada nas instituições de ensino superior politécnico em Portugal (Patrício et al., 2018).

Frølich et al. (2013) sugerem que as instituições de ensino superior são organizações com multitarefas, caracterizadas por um entendimento insuficiente sobre as relações entre objetivos e resultados em relação às tarefas mais intangíveis das instituições de ensino superior (ensino, investigação e terceira missão) que por si só levam à ambiguidade dos objetivos.

\section{Considerações finais}

Pretendemos com esta reflexão distanciar daquilo que Burton R. Clark (1973) criticava nos estudos sociológicos sobre o ensino superior: a miopia do detalhe quantitativo em excesso e a superficialidade dos rótulos. A tipologia que definimos a partir da análise dos dados realça a existência de lógicas diferentes de instituições de ensino politécnico dentro de um mesmo sistema, não só evidenciando o foco predominante de ação de cada uma mas também identificando outras missões que ficam por cobrir, num ensino superior cada vez mais multi-missionário.

Perante os resultados obtidos, é possível afirmar que uma "nova era politécnica" do ensino superior está bem presente em Portugal, com uma nova lógica de ação das instituições de ensino politécnico envolta num novo paradigma de formação politécnica concretizado essencialmente em três campos de ação no momento atual da vida das instituições de ensino politécnico: formação pós-graduada, investigação e internacionalização. 
Ao longo da análise dos dados relativos à pesquisa de diagnóstico foi possível observar uma diversidade de situações e ações por parte das instituições de ensino politécnico, que resultam em perfis distintos: educativo, quando nos seus horizontes de ação estão sobretudo contempladas ações e objetivos relacionados com a formação graduada; científico, apostando sobretudo na investigação experimental e aplicada; e empreendedor, pela ligação forte que apresentam à comunidade, ainda que este perfil requeira uma análise mais aprofundada aos tipos de parceria e aos objetivos estratégicos dessas parcerias. Importa realçar que, passada mais de uma década sobre esse primeiro diagnóstico, a dimensão internacionalização ganharia agora uma outra força, bem ilustrada pelas estatísticas atuais e pela agenda estratégica das instituições de ensino superior em geral e de ensino politécnico em particular.

Assumindo que no limite existirão tantos perfis quantas instituições de ensino superior, a definição de uma tipologia permite constituir-se como uma estratégia eficiente para o controle de características institucionais em investigação académica e para o desenvolvimento de políticas direcionadas a diferentes tipos de instituições (Shin, 2009). A falta de uma construção tipológica no quadro das políticas públicas de ensino superior pode resultar numa política unilateral que, por estar baseada em tendências modais, possa ser ineficiente em termos de implementação (Shin, 2009).

Os resultados de classificação tipológica deste estudo foram baseados em dados de 2010, com um desenho de investigação muito específico e orientado para o que na altura eram as missões das instituições de ensino superior. Nem dez anos passados, novos desafios e missões foram surgindo ou se consolidando, o que faz com que esta tipologia possa e deva ser alvo de atualização, da mesma forma que outras, como a da Fundação Carnegie, vêm sendo atualizadas continuamente. A proposta que lançamos é, a curto prazo, revisitarmos estes e outros indicadores estatísticos, de forma a revalidar ou reajustar esta tipologia, na certeza de que a diversidade de lógicas de ação continuará a existir, assim o paradigma da pós-modernidade continue a envolver a educação superior. Consideramos ser necessário e pertinente, para validar estas conclusões, a replicação do estudo realizado em 2010.

Seria igualmente interessante utilizar este modelo de análise, aplicado a um sistema de ensino superior binário, em outros países com um sistema de ensino superior similar e sobre o qual uma das vertentes - a vertente mais técnica e mais profissionalizante- careça de um conhecimento mais aprofundado sobre os modos e campos de ação das suas instituições de ensino.

Na base da premissa de que o ensino superior será tanto mais forte quanto maior diversidade existir nas missões das instituições (Mourato, 2014), os estudos de natureza sociológica sobre a educação superior deverão permitir dar resposta a essa necessidade de uma contínua classificação das instituições de ensino superior. Tal acontece sobretudo com o propósito de melhor orientar as políticas públicas de ensino superior, num sistema em que o Estado influencia as missões que as instituições de ensino superior podem adotar (regulando-as de forma estrita ou, ao invés, oferecendo considerável autonomia), e, paralelamente, os mercados em que as instituições de ensino superior podem entrar (Frølich et al., 2013). Deixamos, no entanto, para posteriores reflexões um debate sobre essa dupla influência do Estado sobre as instituições de ensino superior politécnico. Para já, esperamos que o contributo maior deste artigo seja uma reflexão atual sobre os perfis de instituições de ensino politécnico e as suas lógicas de ação em Portugal, que consideramos ser necessária de ser trazida para cima da mesa. 


\section{Referencias}

Alves, E. (2015), Estudantes internacionais no ensino superior português: motivações, expectativas, acolhimento e desempenho, AltoComissariado para as Migrações (ACM, I.P.), <https:// www.om.acm.gov.pt/documents/58428/179891/ Tese46_baixa-resol.pdf/eded6051-9316-419e-9f0989b67f61da0a>.

Amaral, A., B. J. Ferreira, M.L. Machado-Taylor, R. Santiago (2006), Modelos de governação e gestão dos institutos politécnicos portugueses no contexto europeu, Castelo Branco, Associação de Institutos Politécnicos do Centro.

Bathmaker, A-M., G. Brooks, G. Parry, D Smith (2007), "Dual-Sector Further and Higher Education: Policies, Organisations and Students in Transition”, em Annual Conference of the Society for Research into Higher Education, Brighton, <http://www.sheffield.ac.uk/ content/1/ c6/05/67/89/Article_for_RPiE\%5B2\%5D.doc> (Consulta: fevereiro de 2010).

Clark, B. R. (1973), "Development of the Sociology of Higher Education", Sociology of Education, vol. 6, núm. 1, pp. 2-14, <http://www.jstor.org/stable/2112203> Consulta: março de 2011).

CHEPS (2013), Policy challenges for the Portuguese polytechnic sector: A report for the Portuguese Polytechnics Coordinating Council (CCISP), Lisboa, Conselho Coordenador dos Institutos Superiores Politécnicos.

European University Association (EUA) (2013), Portuguese higher education: a view from outside, Bruselas, European University Association.

Frølich, N., J. Huisman, S. Slipersæter, P. C. Pimentel Botas (2013), "A "reinterpretation "of "institutional transformations "in "European "higher "education: strategising pluralistic organisations in multiplex environments", Higher Education, núm. 65, pp. 79-93.

Galego, C. (2016), "Políticas educativas e ensino superior: análise da internacionalização no contexto de trabalho da profissão académica em Portugal", Revista Internacional de Educação Superior, vol. 2, núm. 1, pp. 10-30.

Grácio, S. (1998), Ensinos técnicos e politica em Portugal (1910/1990), Lisboa, Instituto Piaget.
Horta, H., J. Huisman, M. Heitor (2008), "Does competitive research funding encourage diversity in higher education?", Science and Public Policy, vol. 35, núm. 3, April, pp. 146-158.

Manfreda, K. L., J. Daikeler, M. Bosnjak (2008), "Web Surveys versus other Survey Modes: A Meta-Analysis Comparing Response Rates", International fournal of Market Research, vol. 50, núm. 1, pp. 79-104.

Mora, J.-G. (2018), "Universidades: mitos, modas y tendencias", Revista Iberoamericana de Educación Superior (RIES), vol. 9, núm. 24, pp. 3-16, <https://www.ries. universia.unam.mx/index.php/ries/article/view/262>

Mourato, J. (2014), "O ensino superior politécnico em Portugal - presente e futuro", Revista FORGES - Fórum de Gestão do Ensino Superior nos Países e Regiões de Lingua Portuguesa, vol. 1, núm. 1, pp. 109-143, <http://hdl. handle.net/10316.2/36222> (Consultado: setembro de 2018).

Patrício, M. T., J. E. Alves, E. Alves, R. Valente (2018), "Avaliação do desempenho da investigação aplicada no ensino superior politécnico-Construção de um modelo", Sociologia, Problemas e Práticas, núm. 86, pp. 69-89.

Pedreira, I. (2014), Os estudantes da Comunidade dos Países de Lingua Portuguesa (CPLP) no ensino superior em Portugal, Lisboa, Direção de Estatísticas da Educação e Ciência, <http://www.dgeec.mec.pt/np4/68/\%7B \$clientS ervletPath $\% 7 \mathrm{D} /$ ?newsId $=69 \&$ fileName=relat_rio_ Estudantes_CPLP_21052015.pdf>

Pires da Rosa, M. J., P. M. Saraiva, H. Diz (2001), "The development of an Excellence Model for Portuguese higher education institutions", Total Quality Management, vol. 12, núm. 7-8, pp. 1010-1017.

OCDE (1993), Manual de Frascati, 1993: propuesta de norma práctica para encuestas de investigación y desarrollo experimental, OCDE Publicaciones.

Rossi, F. (2010), "Massification, competition and organizational diversity in higher education: Evidence from Italy", Studies in Higher Education, vol. 35, núm. 3, pp. 277-300. 
Santos, B. S. (1999), Pela mão de Alice: o social e o político na pós-modernidade, Porto, Afrontamento (7 edição).

Shin, J. C. (2009), "Classifying higher education institutions in Korea: a performance-based approach", Higher Education, núm. 57, pp. 247-266.

Teixeira, P. N., V. Rocha, R. Biscaia, M. Fonseca Cardoso (2011), "Competition and diversity in higher education: an empirical approach to specialization patterns of Portuguese institutions", Higher Education, núm. 63, pp. 337-352, <http://link.springer.com/article/10.1007/ s10734-011-9444-9> (Consulta: dezembro de 2016).

Urbano, C. (2015), O ensino politécnico em Portugal -A construção de uma identidade em tempos de mudança (entre os finais do séc. XX e o início do novo milénio), Lisboa, Novas Edições Acadêmicas.

Veiga, R. B. (2011), "Internacionalização das Instituições de Ensino Superior em Portugal: proposta de metodologia para construção de indicador do grau de internacionalização", Dissertação de mestrado em Negócios Internacionais, Escola Superior de Tecnologia e Gestão do Instituto Politécnico de Leiria, <https:// iconline.ipleiria.pt/bitstream/10400.8/544/1/ MNI\%20Rita\%20Veiga.pdf> (Consulta: setembro de 2018).

\section{Cómo citar este artículo:}

Urbano, Cláudia (2020), "Lógicas diferentes de instituições de ensino superior num mesmo sistema: os perfis das instituições de ensino politécnico em Portugal”, Revista Iberoamericana de Educación Superior (RIES), vol. XI, núm. 32, pp. 149-162, DOI: https://doi.org/10.22201/iisue.20072872e.2020.32.819 [Consulta: fecha de última consulta]. 